\title{
Risk-Informed Analysis of the Large Break Loss of Coolant Accident and PCT Margin Evaluation with the RISMC Methodology
}

\author{
T.H. Liang ${ }^{\mathrm{a}}$, K.S. Liang ${ }^{\mathrm{a}^{*}}$, C.K. Cheng ${ }^{\mathrm{a}}$, B.S. Pei ${ }^{\mathrm{a}}$, E. Patelli ${ }^{\mathrm{b}}$ \\ a Institute of Nuclear Engineering and Science, National Tsing Hua \\ University, \\ 101 Sec. 2, Kuang-Fu Road, Hsinchu 30013, Taiwan \\ Tel: 886-926082901, fax: 886-3-5165488, email: \\ ksliang@alum.mit.edu b Institute of Risk and Uncertainty, \\ University of Liverpool, \\ Room 610, Brodie Tower, L69 3GQ, United Kingdom
}

Abstract

For general design basis accidents, such as SBLOCA and LBLOCA, the traditional deterministic safety analysis methodologies are always applied to analyze events based on a so called surrogate or licensing sequence, without considering how low this sequence occurrence probability is. In the to-be-issued 10 CFR 50.46a, the LBLOCA will be categorized as accidents beyond design basis and the PCT margin shall be evaluated in a risk-informed manner. According to the risk-informed safety margin characterization (RISMC) methodology, a process has been suggested to 
evaluate the risk-informed PCT margin. Following the RISMC methodology, a load spectrum of PCT for LBLOCA has been generated for the Taiwan's Maanshan Nuclear Power plant and 14 probabilistic significant sequences have been identified. 
It was observed in the load spectrum that the conditional PCT generally ascends with the descending sequence occurrence probability. With the load spectrum covering both aleatory and epistemic uncertainties, the risk-informed PCT margin can be evaluated by either expecting value estimation method or sequence probability coverage method. It was found that by comparing with the traditional deterministic methodology, the PCT margin evaluated by the RISMC methodology can be greater by $44-62 \mathrm{~K}$. Besides, to have a cumulated occurrence probability over $99 \%$ in the load spectrum, the occurrence probability of the sequence referred is about $5.07 * 10^{-3}$, whereas for the traditional surrogate or licensing sequence generally applied in the deterministic methodology, the occurrence probability is only about $5.46 * 10^{-5}$. Key Words: Risk-Informed, LBLOCA Sequences, PCT margin, Deterministic, Probabilistic, RISMC Methodology

The number of manuscript folios: 37, including 9 figures and 3 tables 


\section{Introduction}

A traditional deterministic safety analysis methodology is generally applied to analyze design basis accidents (DBA) based on a so called surrogate or licensing sequence, without considering how low this sequence occurrence probability is.

Although the occurrence probability of such licensing sequence generally is lower, it do satisfy all required conservative assumptions for DBA licensing analysis, such as single-failure criteria, loss of off-site power, et al.. In traditional licensing safety analysis, other than the chosen surrogate sequence, calculation uncertainty also needs to be considered, which involves both model uncertainty and plant status uncertainty. By proper consideration of these two uncertainties (IAEA, 2003), calculation uncertainty can be well quantified. In general, these two types of uncertainties can be categorized as epistemic uncertainty. Traditionally, only conservative Appendix K methodology is allow to perform LBLOCA licensing analysis. Whereas, in the revised 10 CFR 50.46 (USNRC, 1988), best estimate plus uncertainty (BEPU) has been allowed and regulatory guide 1.157 (USNRC, 1989) clearly states how to quantify associated calculation uncertainty. Although BEPU methodology (Boyack, et al., 1989) is legally allowed to replace conservative Appendix K methodology (USNRC, 1974), it is still a revised deterministic methodology based on a predetermined licensing sequence. 
In general, all uncertainties can be categorized into epistemic uncertainty and aleatory uncertainty. Epistemic uncertainty results from the "imperfect knowledge” regarding values of parameters of the underlying computational model, whereas aleatory uncertainty results from the effect of "inherent randomness" or "stochastic variability”. Aleatory uncertainty represents the nondeterministic and unpredictable random nature of the performance of the system and its components. In the current advanced BEPU licensing safety analysis methodologies (Westinghouse, 2005) (Martin, R.P., 2005) (Framatome ANP, 2001), only epistemic uncertainty is considered which involves both best-estimate mechanistic models and realistic plan status parameters. On the contrary to a surrogate sequence generally applied in traditional deterministic methodologies, to dealing with the aleatory uncertainty, a group of sequences should be identified for a particular initiating event with PSA skill (Henley and Kumamoto, 1981) to take into account systems or components failure by random probability.

In the current 10 CFR 50.46, both SBLOCA and LBLOCA are considered as design basis accidents, and only deterministic methodologies based on a conservative surrogate or licensing sequence are granted for LOCA licensing safety analysis. However, as stated in the to-be-issued 10 CFR 50.46a (USNRC, 2010a ), "alternative acceptance criteria for emergency core cooling systems for 
light water nuclear power reactors”, any LOCAs with break size greater than the transition break size (USNRC, 2010b) can be considered as accidents beyond the design basis. It was also stated in the paragraph (e) (3) of 10 CFR 50.46a, calculations for LBLOCA may take credit for the availability of offsite power and do not require the assumption of a single failure. Besides, Realistic initial conditions and availability of safety-related and non-safety-related equipment may be assumed if supported by plant-specific data or analysis.

As also stated in the to-be-issued 10 CFR 50.46a, any applicant, permit holder, or licensee or other entity who wishes to make changes enabled by this new rule, to the facility, facility design, or procedures or to the technical specifications shall perform a risk-informed evaluation. According to the 10 CFR 50.46a, the risk-informed assessment process must include methods for evaluating compliance with the risk criteria, defense-in-depth criteria, safety margin criteria, and performance measurement criteria. As required, when evaluating the risk-informed safety margin, uncertainties considered should include phenomenology, modeling, plant construction, plant operation, etc. (USNRC, 2010c). The risk-informed safety margin therefore refers to a view of margin based on a broader perspective compared to the safety margin determined by traditional deterministic LOCA methodologies. Therefore, according to the 
proposed 10 CFR 50.46a, statements about margin now need to have meaning not only with respect to a design-basis event sequence, but more generally with reference to a non design-basis sequence, or even group of sequences: a success path or a family of success paths. The newly developed risk-informed safety margin characteristic (RISMC) methodology (Hess, 2009) (Smith, et al., 2012) (Kang, et al., 2013) (Sherry, et al., 2013) can be applied to calculate the risk-informed safety margin for LBLOCA to satisfy the to-be-issued 10 CFR 50.46a.

The RISMC methodology is a systematic approach to consider both aleatory and epistemic uncertainties. To replace the surrogate-based decision making, the main scope of the RISMC methodology is to generate a probabilistic load spectra as shown in Figure 1, and quantify the safety margin in a proper risk-informed manner. The RISMC methodology systematically combines both probabilistic and mechanistic approaches to estimate the safety margin. The probability analysis is represented by the stochastic risk analysis with PSA techniques involving both event tree and fault tree analysis, whereas mechanistic analysis is represented by the physical calculation with evaluation models satisfying requirements set forth in the to-be-issued 10 CFR 50.46a. Evaluation models can be either conservative Appendix K model or realistic models with uncertainty 
quantification. With the combination of both probabilistic and mechanistic analyses, both aleatory uncertainty and epistemic uncertainty can be well quantitatively addressed, and a risk-informed peak cladding temperature (PCT) margin of LBLOCA can be evaluated. 


\section{Process to Evaluate the Risk-Informed PCT Margin with RISMC}

\section{Methodology}

To perform risk-informed LBLOCA analysis with the RISMC methodology, a load spectrum of LBLOCA will be generated and both aleatory and epistemic uncertainties will be quantified. The following process was recommended to calculate the licensing PCT of a LBLOCA to satisfy the risk-informed safety margin evaluation requirement stated in the to-be-issued 10 CFR 50.46a.

(1) Identification of the LBLOCA Sequences

With the probabilistic safety assessment techniques (Kumamoto \& Henley, 1996), possible scenarios or sequences of LBLOCA will be identified.

(2) Quantification of LBLOCA sequence occurrence probabilities

To address the aleatory uncertainty, the occurrence probability of each sequence (sequence probability, SP) will be quantified by both event tree and fault tree analysis and consequently, probabilistic significant sequences can be identified.

(3) Calculation of the nominal PCT for LBLOCA sequences

As required by the to-be-issued 10 CFR 50.46a, a proper evaluation model which meets the requirement of traditional LBLOCA licensing calculation shall be applied to perform LBLOCA analysis with nominal settings of both 
models and plant parameters to calculate the nominal conditional peak

cladding temperature $\left(\mathrm{CPCT}_{\mu}\right)$ for each probabilistic significant LBLOCA

sequence.

(4) Conducting a preliminary load spectrum of LBLOCA

By having the $\mathrm{CPCT}_{\mu}$ of each probabilistically significant scenarios or sequences and associated sequence probability, a preliminary load spectrum of LBLOCA can be conducted;

(5) Quantification of calculation uncertainty of the preliminary load spectrum To account for the epistemic or calculation uncertainty of CPCT resulting from physical models and plant status for the preliminary load spectrum, the CPCT at 95\% coverage and 95\% confidence level (CPCT $95 / 95)$ will be calculated with proper methodology (Westinghouse, 2005) (Liang, et al., 2011) (Ludmann, M., 1999) on the traditional surrogate or licensing sequence, and quantify the difference between the $\mathrm{CPCT}_{95 / 95}$ and the nominal $\mathrm{CPCT}_{\mu}$ calculated in step (3) on the surrogate sequence: $\Delta$

$$
\underset{, \text { ss }}{\triangle P C T_{u n, s s}}=C P C T_{95 / 95, s s}-C P C T_{\mu}
$$

(6) Conducting the final load spectrum for LBLOCA

With the calculation uncertainty $\left(\Delta \mathrm{PCT}_{\mathrm{un}, \mathrm{ss}}\right)$ evaluated on the surrogate sequence, the preliminary load spectrum of LBLOCA will be shifted, as 
shown in Figure 2, to reflect the calculation uncertainty, instead of calculating the $\mathrm{CPCT}_{95 / 95}$ for each sequence. Therefore, the final CPCT for sequence "i" will be:

$C P C T_{\mu+\Delta, i}=C P C T_{\mu, i}+$ $\triangle P C T_{u n, s s}$

and the PCT margin of sequence "i” can then be calculated as:

$$
\Delta P C T_{S M, i}=P C T_{S L}-P C T_{\mu+\Delta}
$$

Where $\mathrm{PCT}_{\mathrm{SL}}$ is the safety limit required by the regulation and generally is 1477.5K $\left(2200.0^{\circ} \mathrm{F}\right)$.

(7) The Risk-informed PCT Safety Margin Characterization The risk-informed PCT safety margin $\left(\Delta \mathrm{PCT}_{\mathrm{RI}}\right)$ can be calculated by two different methods; the first one is the expecting value estimation method and the second one is the sequence probability coverage method. In the first method, the risk-informed safety margin can be mathematically defined as (Gavrilas, M., et al., 2007):

$$
\Delta P C T_{R I}=\frac{\sum_{i} \Delta P C T_{S M, i} * S P_{i}}{\sum_{i}{ }_{i}}
$$

Note that when $\triangle \mathrm{PCT}_{\mathrm{SM}, \mathrm{i}}$ of any sequence "i" is less than 0.0 , it will be set as 
shown in Figure 2, to reflect the calculation uncertainty, instead of calculating 0.0 to reflect the fact that the risk-informed safety margin of PCT can only be

contributed by those sequence with positive $\Delta \mathrm{PCT}_{\mathrm{SM}, \mathrm{i}}$. Moreover, note that the 
summation of total sequence probability is equal to unity.

Alternatively, in the second sequence probability coverage method, the risk-informed peak cladding temperature $\left(\mathrm{PCT}_{\mathrm{RI}}{ }^{99 \%}\right)$ will be defined by a particular sequence with a cumulated occurrence probability greater than 99\%. Therefore, the $\mathrm{PCT}_{\mathrm{RI}}{ }^{99 \%}$ of the second method can be defined by the final $\mathrm{CPCT}_{\mu+\Delta}$ of sequence $\mathrm{K}$ :

$$
P C T_{\mathrm{RI}}^{99 \%}=C P C T_{\mu+\Delta, k}
$$

Where the sequence " $\mathrm{K}$ " is determined by the summation of all the sequence probabilities $\left(\Sigma \mathrm{SP}_{1-\mathrm{k}}\right)$ from the sequence with the lowest $\mathrm{CPCT}_{\mu+\Delta, \mathrm{i}}$ by ascending order until the $\Sigma \mathrm{SP}_{1-\mathrm{k}}$ is greater than $99 \%$.

$$
\begin{array}{ll}
\Sigma S P_{1-k} & =\sum^{k} S P_{i} \geq 99 \%, \\
\text { with } & C P C T_{\mu+\Delta, i} \leq C P C T_{\mu+\Delta}
\end{array}
$$

Therefore, by the second sequence probability coverage method, the risk-informed safety PCT margin will be:

$$
\Delta P C T_{R I}=P C T_{S L}-P C T_{R I}^{99 \%}
$$

The above seven major steps were summarized in Figure 3 for illustration. In the following sections, the Taiwan’s Maanshan PWR plant (Westinghouse, 1987) was referred to demonstrate how to evaluate the risk-informed PCT safety margin for LBLOCAs. 


\section{LBLOCA sequences identification and quantification}

According to the to-be-issued 10 CFR 50.46a, LBLOCA will be considered as beyond design basis accidents and traditional deterministic licensing sequence can be relaxed. Therefore, to address the effect of system and component random failure caused by aleatory uncertainty, with probability and risk assessment techniques all possible LBLOCA sequences will be identified and the occurrence probability of each sequence (sequence probability, SP) can be quantified. In the short term LBLOCA PCT analysis, possible sequences were configured by the random combination of the individual safety injection system available.

Considering Taiwan’s Maanshan nuclear plant, a traditional 3-loop Westinghouse PWR, emergence core cooling system (ECCS) includes high head injection system, low head injection system and accumulators for medium head injection. All above safety systems satisfy the single failure criteria and redundancy criteria. Therefore, in the headings of the event tree analysis, all possible system combinations are considered and consequently 108 different event sequences are degenerated. With appropriate fault tree analysis, the occurrence probability of each sequence can be well quantified. The possible system combination of each sequence is shown in the LBLOCA event tree plot (Figure 4) and occurrence probabilities of the top fourteen probabilistic significant LBLOCA 
sequences are summarized in Table 1. 


\section{Probabilistic Load Spectrum of LBLOCA}

As indicated in section 3, fourteen probabilistic significant sequences of LBLOCA of Taiwan's Maanshan nuclear power plant have been identified, as listed in Table 1 . The total occurrence probability of those fourteen probabilistic significant sequences is more than $99.99 \%$ coverage. To generate a load spectrum for the LBLOCA while considering both aleatory and epistemic uncertainties, a two-step approach was adopted as elaborated in section 2. The first step is to generate a preliminary load spectrum by using RELAP5-3D/K (Liang, K.S., et al., 2002a) (Liang, K.S., et al., 2002b) to calculate the nominal conditional PCT $\left(\mathrm{CPCT}_{\mu}\right)$ for each sequence, and the second step is to account for the epistemic or calculation uncertainty of the preliminary load spectrum by using the DRHM methodology (Liang, K.S., 2011). In the DRHM methodology, conservative Appendix K models were adopted to cover model uncertainty, whereas realistic plant status parameters were used with statistical uncertainty analysis.

To calculate the $\mathrm{CPCT}_{\mu}$ of those probabilistic significant sequences in the first step, all the plant status parameters are set as their nominal values, and a conservative plant model for Maanshan LBLOCA analysis (Taiwan Power Company, 2013) is applied, as shown in Figure 5. The $\mathrm{CPCT}_{\mu}$ of the top fourteen probabilistic significant LBLOCA sequences were calculated and the associated 
responses are shown in Figure 6. Moreover, the resulted $\mathrm{CPCT}_{\mu}$ of each probabilistic significant sequence are also summarized in Table 1 and a plot of $\mathrm{CPCT}_{\mu}$ versus associated sequence probability is shown in Figure 7 to represent the preliminary LBLOCA load spectrum of the Maanshan nuclear power plant. It can be observed from the preliminary load spectrum that the $\mathrm{CPCT}_{\mu}$ generally ascends with the descending sequence occurrence probability.

To account for the calculation uncertainty in the second step with DRHM methodology, since conservative Appendix evaluation model (RELAP5-3D/K) is applied, the remaining calculation uncertainty will be the plant status uncertainties. The effect of the plant status uncertainty on PCT calculation was evaluated on the basis of the traditional licensing sequence (sequence LOCAS74 in Table 1). Referring to a typical PWR best estimate LBLOCA licensing analysis (Westinghouse, 2009), important plant parameters were identified and summarized in Table 2 with uncertainty ranges. According to the DRHM methodology, at least 59 trials were randomly generated to quantify the effect of plant status uncertainty. Typical parameter samplings are shown in Figure 8 for illustration and the PCT responses of 59 trials are also shown in Figure 9. By the Wilk’s formula (David and Nagaraja, 1980), the PCT of 95\% percentile and 95\% confidence level can be estimated by the highest PCT amount those 59 trials, 
which is $1337.76 \mathrm{~K}$. With the nominal PCT value of $1289.46 \mathrm{~K}\left(\mathrm{CPCT}_{\mu, \mathrm{ss}}\right)$ and 95/95 PCT value of $1337.76 \mathrm{~K}\left(\mathrm{CPCT}_{95 / 95, \mathrm{ss}}\right)$ evaluated on the licensing sequence, the calculation uncertainty according to Equation (1) caused by plant status uncertainty can be quantified as:

$$
\Delta P C T_{u n, s s}=C P C T_{95 / 95, s s}-C P C T_{\mu}
$$

ss

$$
=48.3 \mathrm{~K}
$$

Accordingly, the preliminary load spectrum will be shifted by $48.3 \mathrm{~K}$

$$
C P C T_{\mu+\Delta, i}=C P C T_{\mu, i}+
$$
$48.3 K$

to reflect the calculation uncertainty. The final $\mathrm{CPCT}_{\mu+\Delta}$ of those fourteen probabilistic significant sequences with calculation uncertainty are listed in the last column in Table 1. 


\section{Risk-Informed PCT Safety Margin Characterization}

With the final load spectrum for LBLOCA as indicated in the last column of

Table 1 , the risk-informed PCT safety margin $\left(\Delta \mathrm{PCT}_{\mathrm{RI}}\right)$ can be calculated by two different methods; the first one is the expecting value estimation method and the second one is the sequence probability coverage method. By using the first expecting value estimation method and data listed in Table 1, the risk-informed safety margin can be mathematically calculated according to Equation (4) as follows:

$$
\begin{aligned}
\underbrace{\Delta P C T_{R I}}_{i S P_{i}} & =\sum \Delta P C T_{M R, i} \\
& \\
& =202.1 \mathrm{~K} \Sigma
\end{aligned}
$$

As for the second sequence probability coverage method, it was found that the summation of the first 3 sequence (LOCAS01, LOCAS55 and LOCAS56) probabilities is $99.3 \%$. Therefore, the third sequence with a value of $1293.42 \mathrm{~K}$ will be applied to define the risk-informed $\mathrm{PCT}_{\mathrm{RI}}{ }^{99 \%}$, and the risk-informed safety margin will be as follows

$$
\begin{gathered}
\Delta P C T_{R I}=P C T_{L S}-P C T_{\mathrm{RI}}^{99 \%} \\
=184.2 \mathrm{~K}
\end{gathered}
$$




\section{Risk-Informed PCT Safety Margin Characterization}

Comparing the risk-informed safety margins evaluated by above two methods, it

can be found that the $\Delta \mathrm{PCT}_{\mathrm{RI}}$ calculated by the sequence probability coverage 
method is reasonably conservative by $17.92 \mathrm{~K}$. Because the occurrence probability was dominated by the first five sequences, it was expected that the risk-informed PCT safety margin evaluated by either the expecting value estimation method or the sequence probability coverage method should not have a significant difference.

It was observed in the Table 1 that in the second sequence probability coverage method, the third sequence (LOCAS56) was applied to define the risk-informed safety margin $\left(\triangle \mathrm{PCT}_{\mathrm{RI}}{ }^{99 \%}\right)$ and its' associated occurrence probability is $5.07 * 10^{-3}$, while the occurrence probability of the traditional licensing sequence (LOCAS74) applied in the classical deterministic methodology is only $5.46 * 10^{-5}$. In the traditional licensing sequence (LOCAS74) only one train of high head and low head injection are available respectively to satisfy single failure criteria. While in sequence referred in the evaluation of risk-informed PCT safety margin ( LOCAS56) to cover 99\% cumulated occurrence probability, there are two trains of high head injection and one train of low head injection available instead. The detailed differences of the first three sequences and the traditional surrogate sequence are summarized in Table 3.

It was also noted that according to the deterministic methodology, the licensing PCT can only be evaluated by the traditional surrogate sequence 
(LOCAS74) and the correspondent value is $1337.76 \mathrm{~K}$ as indicated in Table 1.

Consequently, the traditional deterministic safety margin is only $139.74 \mathrm{~K}$ by applying the DRHM methodology. Therefore, the PCT safety margin of LBLOCA evaluated by the RISMC methodology can be greater by $44.4-62.4 \mathrm{~K}$ than the margin evaluated by the DRHM deterministic methodology. 


\section{Conclusions}

According to the to-be-issued 10 CFR 50.46a, the LBLOCA will be categorized as accidents beyond design basis. Therefore, the risk-informed safety margin characterization (RISMC) methodology has been applied to evaluate the PCT margin in a risk-informed manner for LBLOCA of Taiwan’s Maanshan PWR plant. By following the proposed process to evaluate risk-informed PCT margin, it can be concluded that:

(1) all possible LBLOCA sequences have been conducted by applying traditional PSA technology, 14 probabilistic dominant sequences have been identified and associated occurrence probabilities also have been quantified;

(2) a load spectrum for LBLOCA has been conducted by calculating conditional PCT of each probabilistic significant sequence with proper LOCA evaluation models. Generally the conditional PCT ascends with the descending sequence occurrence probability. In this load spectrum both aleatory and epistemic uncertainties have been considered;

(3) with the load spectrum, the risk-informed PCT can be evaluated by either the expecting value estimation method or the sequence probability coverage method. The risk-informed PCT safety margin was evaluated ranging from 184.2-202.1 K; 
(4) By comparing with the DRHM deterministic methodology, the PCT margin evaluated by the RISMC methodology can be greater by 44.4-62.4 K by using the same LBLOCA evaluation model(RELAP5-3D/K); and

(5) In the RISMC methodology, to have a cumulated occurrence probability over $99 \%$ in the load spectrum, the occurrence probability of the sequence referred in the sequence probability coverage method is $5.07 * 10^{-3}$. While in the deterministic methodology, the occurrence probability of the traditional surrogate or licensing sequence is only $5.46 * 10^{-5}$. The traditional licensing sequence can only have one train of safety injection system to satisfy single failure criteria, while in sequence referred to evaluate the risk-informed PCT safety margin, there are two trains of high head injection and one train of low head injection are available instead. 


\section{Reference}

Boyack et al., 1989. Quantifying Reactor Safety Margins: Application of Code Scaling Applicability and Uncertainty (CSAU) Evaluation Methodology to a Large-Break-Loss-of-Coolant Accident, NUREG/CR-5249.

David, H.A., Nagaraja, H.N., 1980. Order Statistics. A John Wiley \& Sons, Inc.

Farmatome ANP, 2001. Realistic Large Break LOCA Methodology for Pressurized Water Reactor, EMP-2103 (NP).

Gavrilas, M., et al., 2007. Task Group on Safety Margin Action Plan (SMAP) - Safety Margins Action Plan (Final Report), NEA/CSNI/R(2007)9.

Henley, E.J., Kumamoto, H., 1981. Reliability Engineering and Risk Assessment. Prentice-Hall, Inc.

Hess, S.M., et al., 2009. Framework for Risk-Informed Safety Margin Characterization. Electric Power Research Institute, EPRI Report 1019206.

IAEA, 2008. Safety Margins of Operating Reactors- Analysis of Uncertainties and Implication for Decision Making.

Kang D.G., et al., 2013. A Combined Deterministic and Probabilistic Procedure for Safety Assessment of Beyond Design Basis Accidents in Nuclear Power Plant: Application to ECCS performance assessment for design basis LOCA redefinition. Nuclear Engineering and Design 260, 165-174. 
Kumamoto, H., Henley, E.J., 1996. Probabilistic Risk Assessment and Management for Engineers and Scientists. The Institute of Electrical and Electronics Engineers Inc., New York.

Liang, K.S., et al., 2011. Development and Application of a Deterministic-Realistic Bybrid Methodology for LOCA Licensing Analysis. Nuclear Engineering and Design, 241, 1857-1863.

Liang, K.S., et al., 2002a. Development and Assessment of the Appendix K Version of RELAP5-3D for LOCA Licensing Analysis. Nuclear Technology 139, 233-252. Liang, K.S., et al., 2002b. Development of LOCA Licensing Calculation Capability with RELAP5-3D in Accordance with Appendix K of 10 CFR 50. Nuclear Engineering and Design 211, 69-84.

Ludmann, M., Sauvage J.Y., 1999. LBLOCA Analysis Using the Deterministic Realistic Methodology - Application to the 3-Loop Plant. In: $7^{\text {th }}$ International Conference on Nuclear Engineering (ICONE-7413), April 19-23, Tokyo, Japan. Martin, R.P., O'Dell, L.D., 2005. AREVA’s Realistic Large Break LOCA Analysis Methodology. Nuclear Engineering and Design 235, 1713-1725.

Sherry R.R., et al., 2013. Pilot Application of Risk Informed Safety Margin Characterization to a Total Loss of Feedwater Event. Reliability Engineering and System Safety, 117, 65-72. 
Smith, C., et al., 2012. Light Water Reactor Sustainability Program - Risk Informed Safety Margins Characterization (RISMC) Pathway Technical Program Plan, INL/EXT-11-22977.

Taiwan Power Company, 2013. Evaluation of Stretch Power Uprate with LOCA

Analysis for Chinshan, Kuosheng and Maanshan Nuclear Power Plants in Taiwan, TPC-054-98-3656.

U.S. Nuclear Regulatory Commission, 2010a. 10 CFR 50.46a Draft Final Rule Language -- Alternative Acceptance Criteria for Emergency Core Cooling Systems for Light-Water Nuclear Power Reactors. ADAMS Accession no. ML 10120271.

U.S. Nuclear Regulatory Commission, 2010b. Plant-Specific Applicability of Transition Break Size Specified in 10 CFR 50.46a. Draft Regulatory Guide DG-1216.

U.S. Nuclear Regulatory Commission, 2010c. Risk-Informed Changes to Loss-of-Coolant Accident Technical Requirements (10 CFR 50.46a), SECY-10-0161.

U.S. Nuclear Regulatory Commission, 1989. Best-Estimate Calculations of Emergency Core Cooling System Performance. Regulatory Guide 1.157.

U.S. Nuclear Regulatory Commission, 1988. 10 CFR 50.46 -- Acceptance Criteria for Emergency Core Cooling Systems for Light Water Nuclear Power Reactors. 
U.S. Nuclear Regulatory Commission, 1974. Appendix K to Part 50-ECCS Evaluation Models.

Westinghouse Company, 2005. Realistic Large-Break Loss-of Coolant Accident

Evaluation Using the Automated Statistical Treatment of Uncertainty Method, WCAP-16009-p-A.

Westinghouse Company, 1987. Final Safety Analysis Report of Maanshan PWR Plant. Westinghouse Company, 2009. Best-Estimate Analysis of the Large-Break Loss-of-Coolant Accident for Maanshan Units 1 and 2 Nuclear Power Plant Using the ASTRUM Methodology, WCAP-17054. 
Table 1 . Summary of the Top 14 Probabilistic Significant LBLOCA Sequences

\begin{tabular}{|c|c|c|c|}
\hline Sequence & Occurrence Probability & $\mathrm{CPCT}_{\mu},(\mathrm{K})$ & $\mathrm{CPCT}_{\mu+\Delta},(\mathrm{K})$ \\
\hline LOCAS01 & $4.946 \mathrm{E}-01$ & 1224.36 & 1272.66 \\
\hline LOCAS55 & $4.935 \mathrm{E}-01$ & 1229.52 & 1277.82 \\
\hline LOCAS56 & $5.067 \mathrm{E}-03$ & 1245.12 & 1293.42 \\
\hline LOCAS91 & $4.522 \mathrm{E}-05$ & 1263.21 & 1311.51 \\
\hline LOCAS73 & $1.252 \mathrm{E}-03$ & 1264.37 & 1312.67 \\
\hline LOCAS02 & $5.087 \mathrm{E}-03$ & 1276.48 & 1324.78 \\
\hline LOCAS58 & $1.322 \mathrm{E}-05$ & 1278.05 & 1326.35 \\
\hline LOCAS19 & $1.070 \mathrm{E}-04$ & 1287.59 & 1335.89 \\
\hline LOCAS37 & $4.522 \mathrm{E}-05$ & 1289.01 & 1337.31 \\
\hline LOCAS74 & $5.460 \mathrm{E}-05$ & 1289.46 & 1337.76 \\
\hline LOCAS20 & $5.692 \mathrm{E}-05$ & 1293.70 & 1342.00 \\
\hline LOCAS04 & $1.322 \mathrm{E}-05$ & 1331.42 & 1379.72 \\
\hline LOCAS07 & $2.644 \mathrm{E}-05$ & 1429.63 & 1477.93 \\
\hline LOCAS61 & $2.644 \mathrm{E}-05$ & 1499.76 & 1548.06 \\
\hline
\end{tabular}


Table 2. Uncertainties of Major Plant Parameters of Typical PWRs

\begin{tabular}{|c|c|c|c|}
\hline Parameters & Distribution & Min & Max \\
\hline Core thermal power & Uniform & $101.38 \%$ & $102 \%$ \\
\hline $\begin{array}{l}\text { Initial average fluid } \\
\text { temperature }\left(\mathrm{T}_{\text {avg }}\right), \mathrm{K}\end{array}$ & Uniform & 579.71 & 584.15 \\
\hline $\begin{array}{c}\text { Pressurizer pressure }\left(\mathrm{P}_{\mathrm{RCS}}\right) \text {, } \\
\mathrm{kpa}\end{array}$ & Uniform & 15168.47 & 15857.94 \\
\hline $\begin{array}{l}\text { Accumulator liquid volume } \\
\qquad\left(\mathrm{V}_{\mathrm{ACC}}\right), \mathrm{m}^{3}\end{array}$ & Uniform & 27.89 & 28.74 \\
\hline $\begin{array}{l}\text { Accumulator pressure } \\
\qquad\left(\mathrm{P}_{\mathrm{ACC}}\right), \mathrm{kpa}\end{array}$ & Uniform & 4357.49 & 4688.44 \\
\hline $\begin{array}{l}\text { Accumulator temperature } \\
\qquad\left(\mathrm{T}_{\mathrm{ACC}}\right), \mathrm{K}\end{array}$ & Uniform & 310.93 & 338.71 \\
\hline $\begin{array}{l}\text { Safety injection } \\
\text { temperature }\left(\mathrm{T}_{\mathrm{SI}}\right) \text {, }\end{array}$ & Uniform & 282.59 & 322.04 \\
\hline $\begin{array}{l}\text { Peak heat flux hot channel } \\
\text { factor }\left(\mathrm{F}_{\mathrm{Q}}\right)\end{array}$ & $\begin{array}{l}\text { Uniform }(2.137 \pm 0.137) \\
\qquad \& \text { normal }(\sigma=2.6 \%)\end{array}$ & $2.000-4 \sigma$ & $2.274+4 \sigma$ \\
\hline $\begin{array}{l}\text { Peak hot rod enthalpy rise } \\
\text { hot channel factor }\left(\mathrm{F}_{\triangle \mathrm{H}}\right)\end{array}$ & $\begin{array}{l}\text { Normal (mean=1.65, } \\
\qquad \sigma=2.43 \%)\end{array}$ & 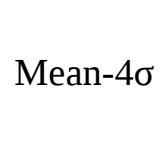 & Mean $+4 \sigma$ \\
\hline $\begin{array}{l}\text { Axial power distribution } \\
\qquad\left(\mathrm{P}_{\text {ВОT }}\right)\end{array}$ & Uniform & 0.22 & 0.44 \\
\hline $\begin{array}{l}\text { Axial power distribution } \\
\qquad\left(\mathrm{P}_{\mathrm{MID}}\right)\end{array}$ & Uniform & 0.31 & 0.43 \\
\hline Off-site power & Random & Loop & Non-loop \\
\hline
\end{tabular}


Table 2. Uncertainties of Major Plant Parameters of Typical PWRs

\begin{tabular}{|c|c|c|c|c|c|}
\hline $\begin{array}{c}\text { Sequence } \\
\text { ID }\end{array}$ & $\begin{array}{l}\text { Sequence } \\
\text { probability }\end{array}$ & $\begin{array}{c}\text { Loss of } \\
\text { off-site } \\
\text { power }\end{array}$ & $\begin{array}{c}\text { High } \\
\text { Head } \\
\text { Injection }\end{array}$ & $\begin{array}{c}\text { ACC } \\
\text { Injection }\end{array}$ & $\begin{array}{c}\text { Low } \\
\text { Pressure } \\
\text { Injection }\end{array}$ \\
\hline LOCAS01 & $4.946 \mathrm{E}-01$ & no & 2 trains & 3 & 2 trains \\
\hline LOCAS55 & $4.935 \mathrm{E}-01$ & yes & 2 trains & 3 & 2 trains \\
\hline LOCAS56 & $5.067 \mathrm{E}-03$ & yes & 2 trains & 3 & 1 train \\
\hline LOCAS74 & $5.460 \mathrm{E}-05$ & yes & 1 train & 3 & 1 train \\
\hline
\end{tabular}




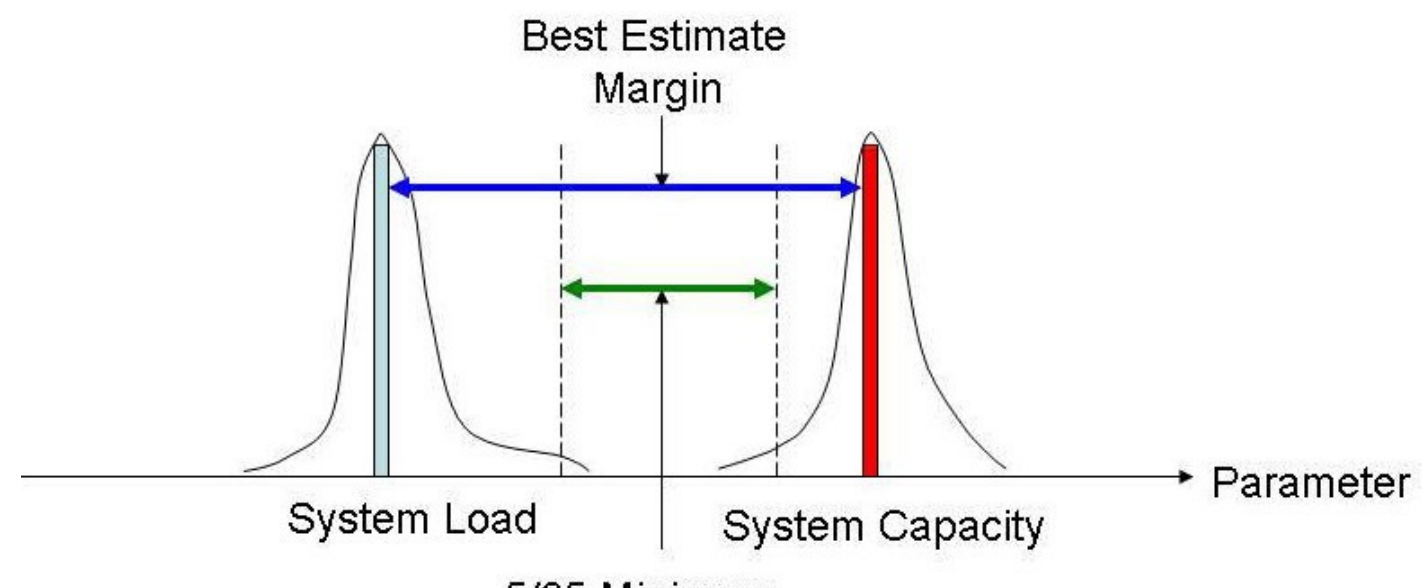

5/95 Minimum

Available Margin

Figure 1. Load Spectrum (Hess, 2009) 


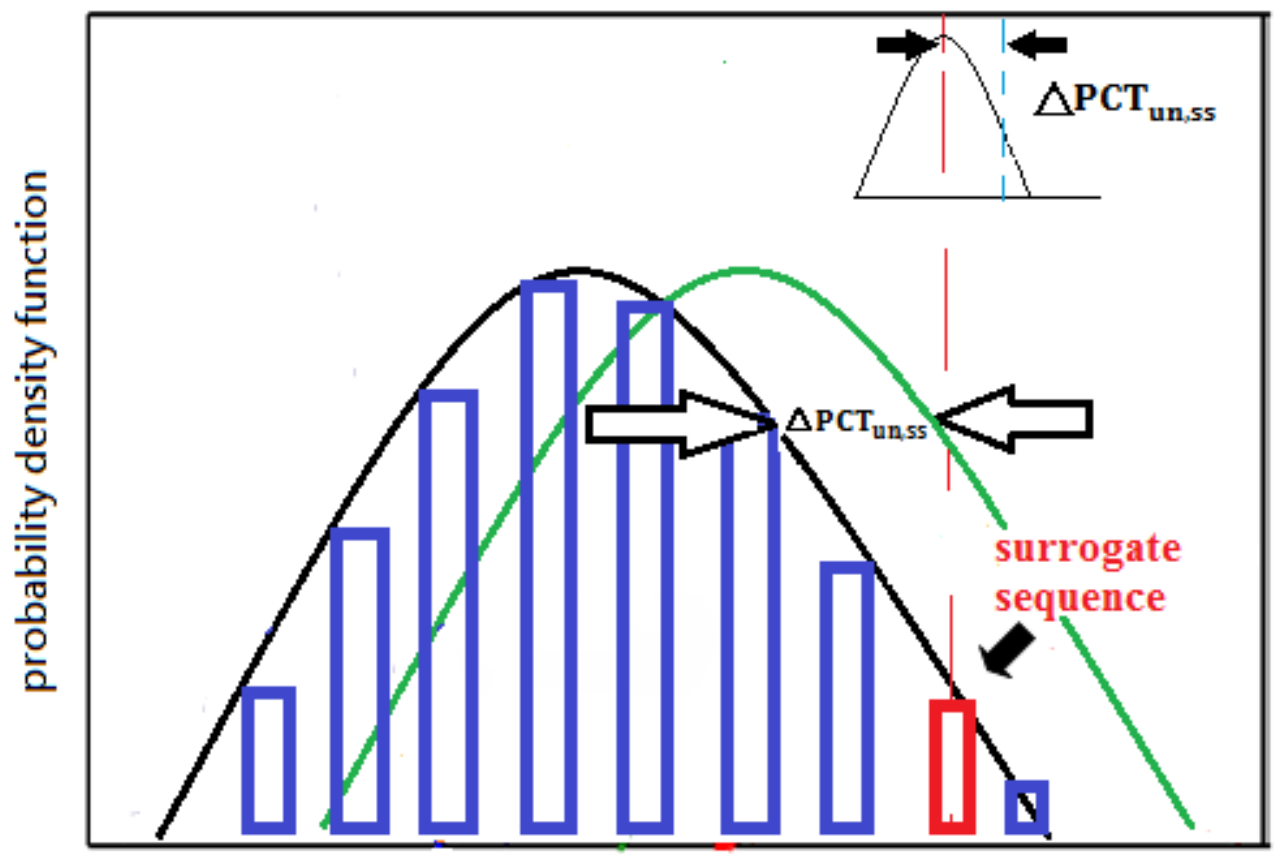

safety variable, e.g., PCT

Figure 2. Shifted Load Spectrum to Reflect Calculation Uncertainty 


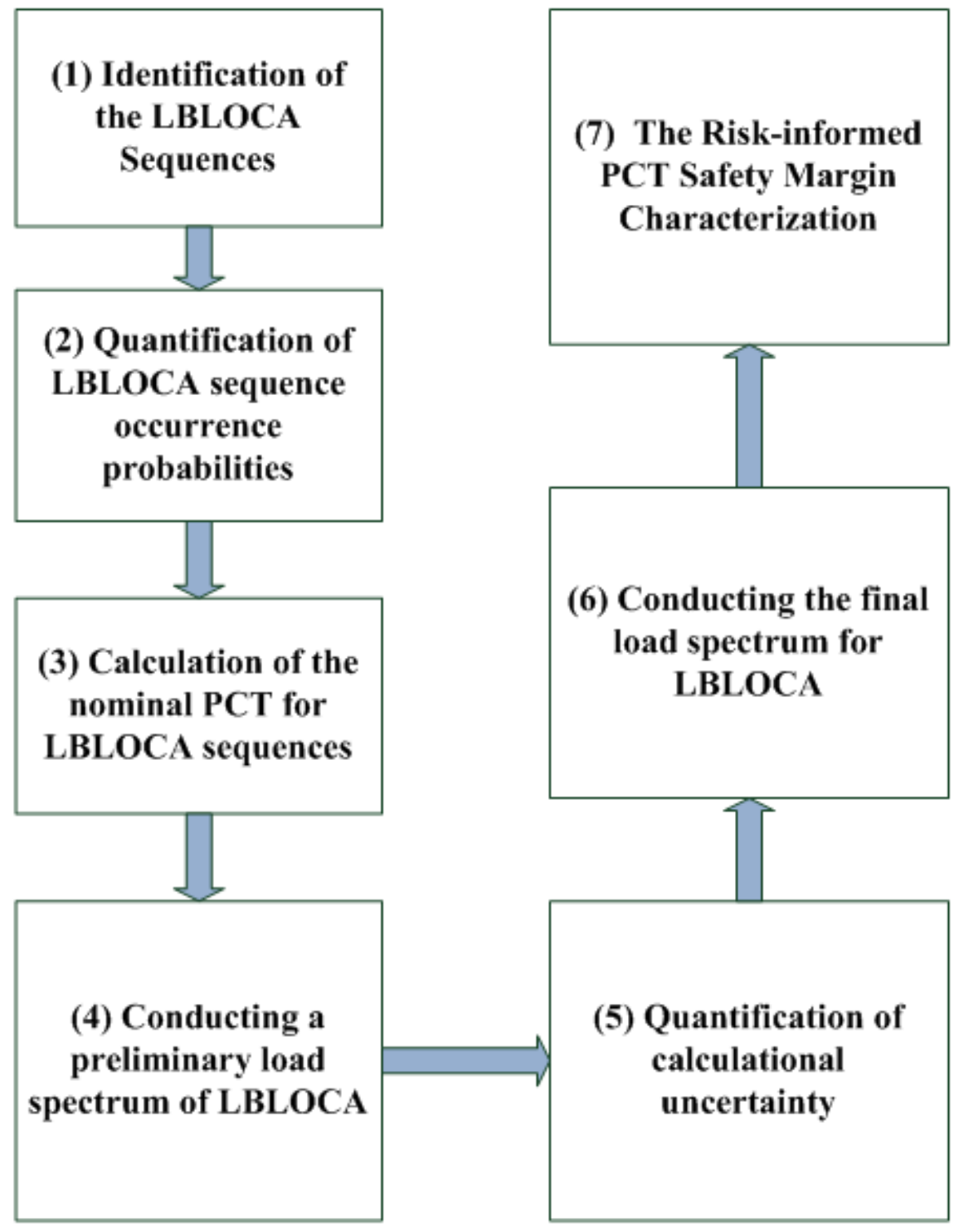

Figure 3. Process for Risk-informed PCT Safety Margin Evaluation 


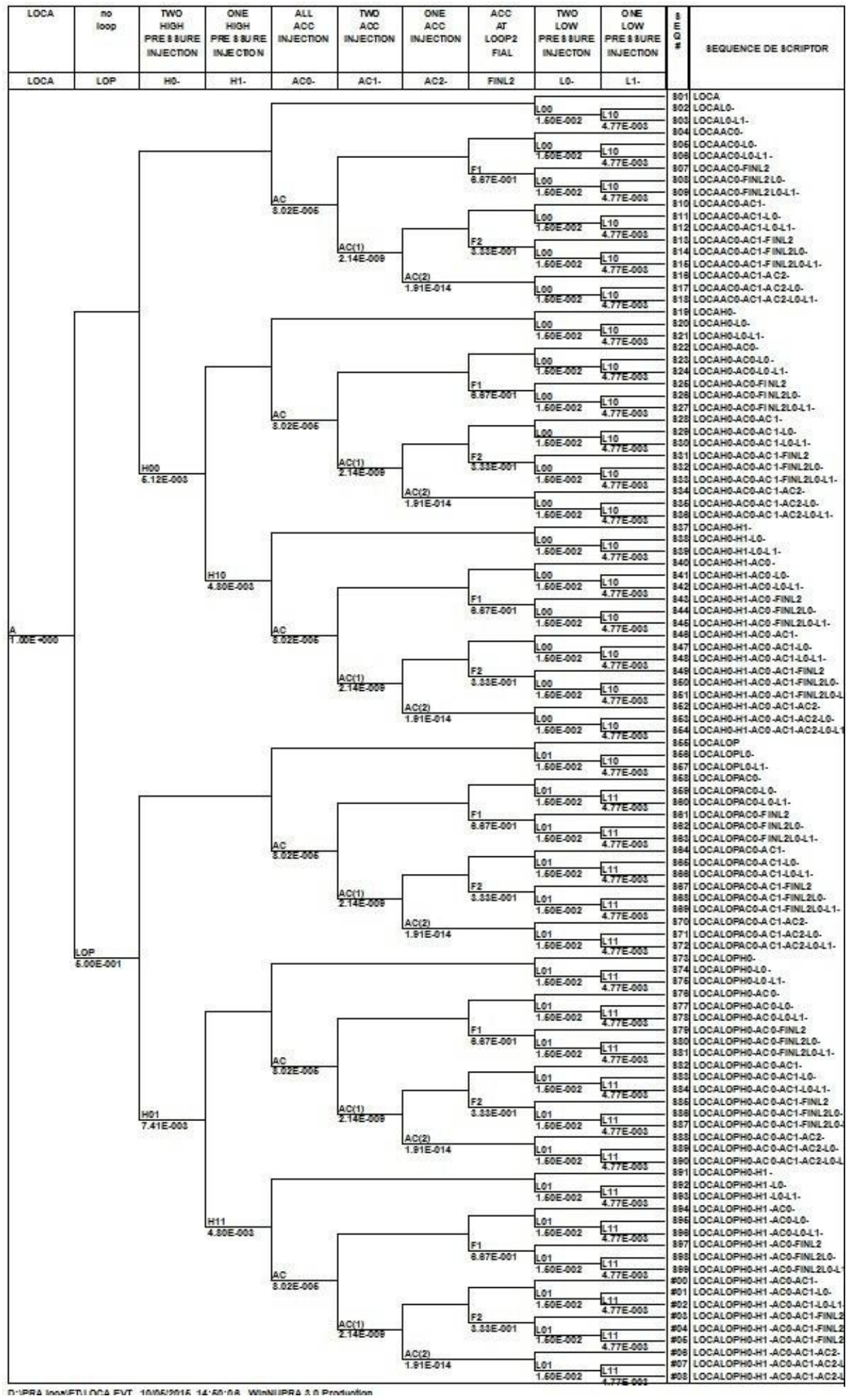

Figure 4. Sequence Identification and Quantification for LBLOCA 


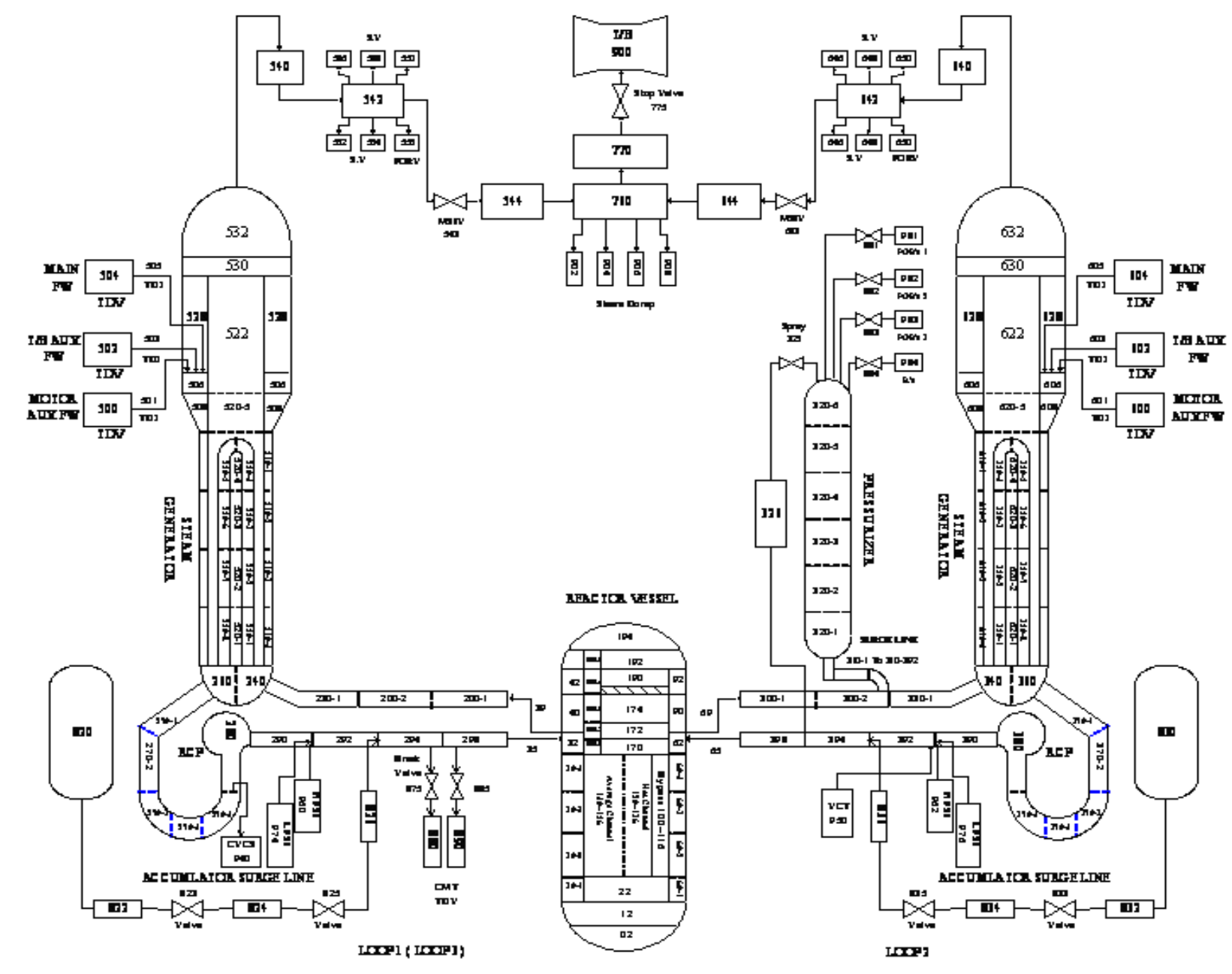

Figure 5. RELAP5 Nodding Diagram for Maanshan PWR LBLOCA Analysis 


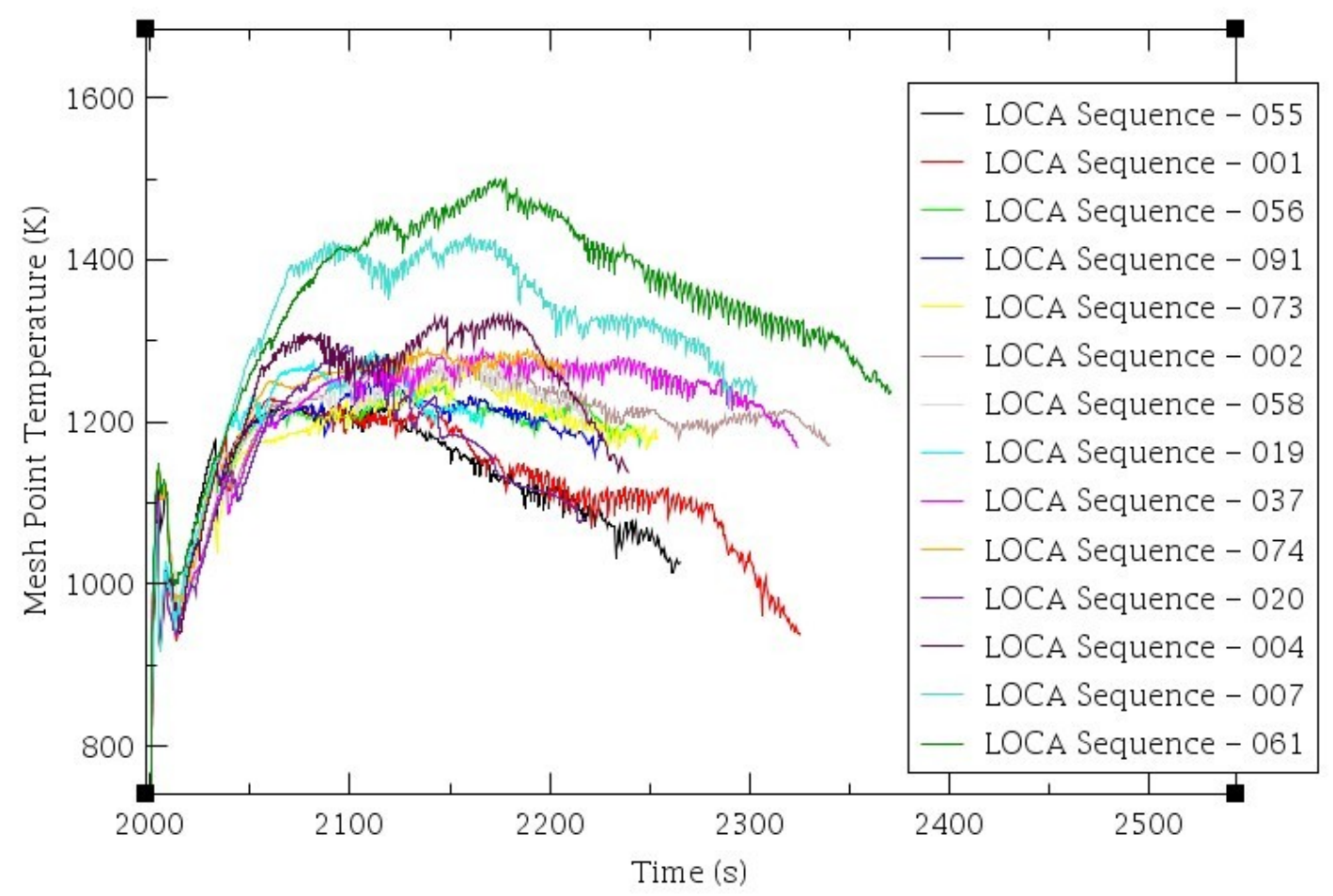

Figure 6. CPCT Responses for the Probabilistic Significant LBOCA Events 


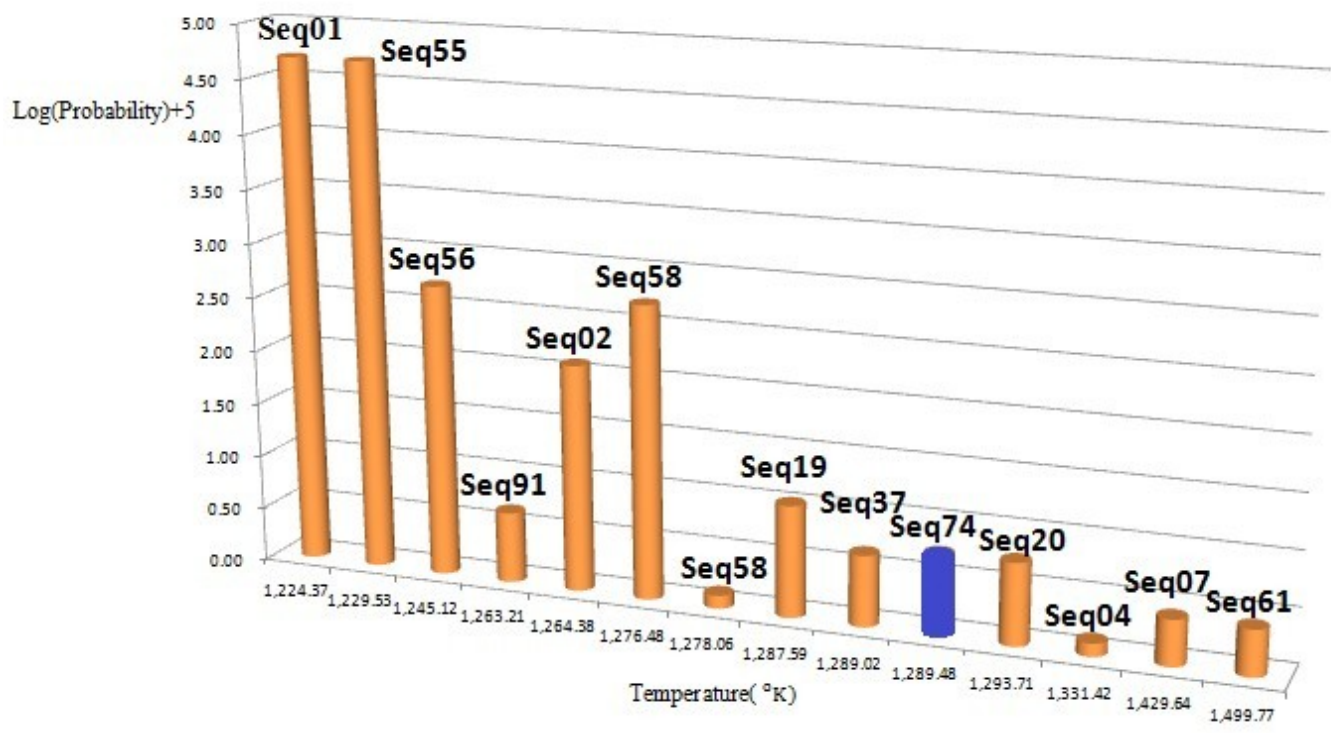

Figure 7. Preliminary Load Spectrum for Maanshan PWR LBLOCA 
FO
Peaking
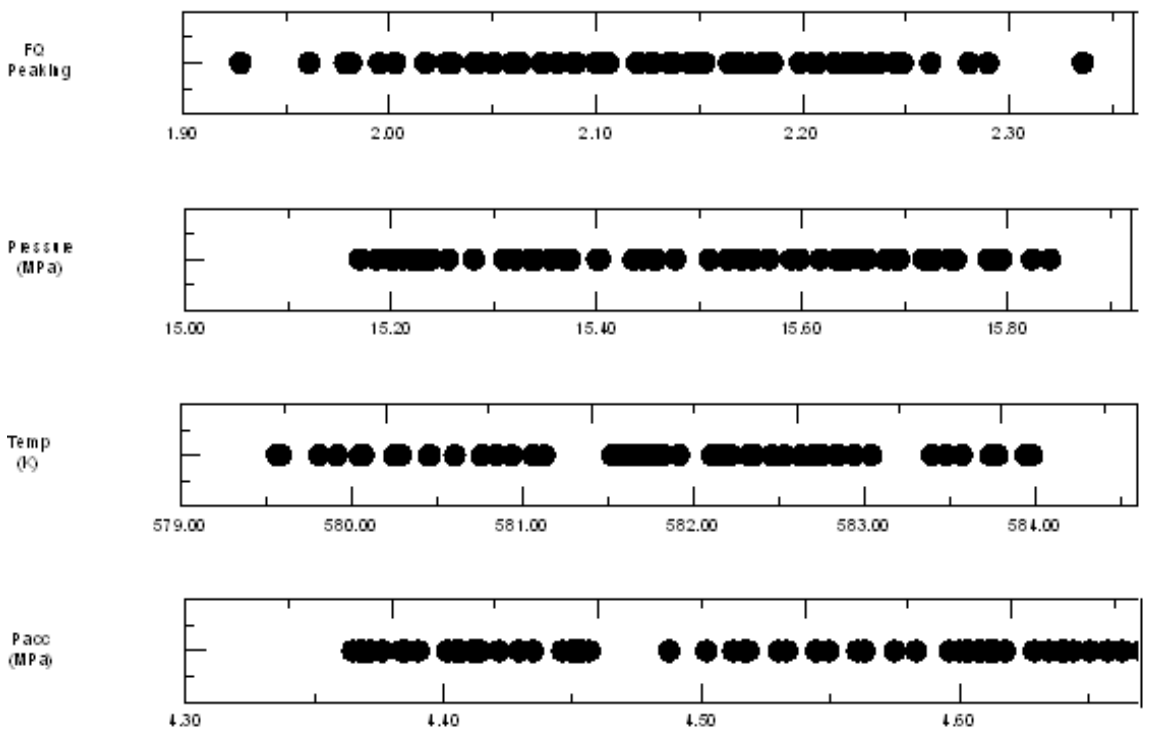

Figure 8. Typical Parameter Samplings 


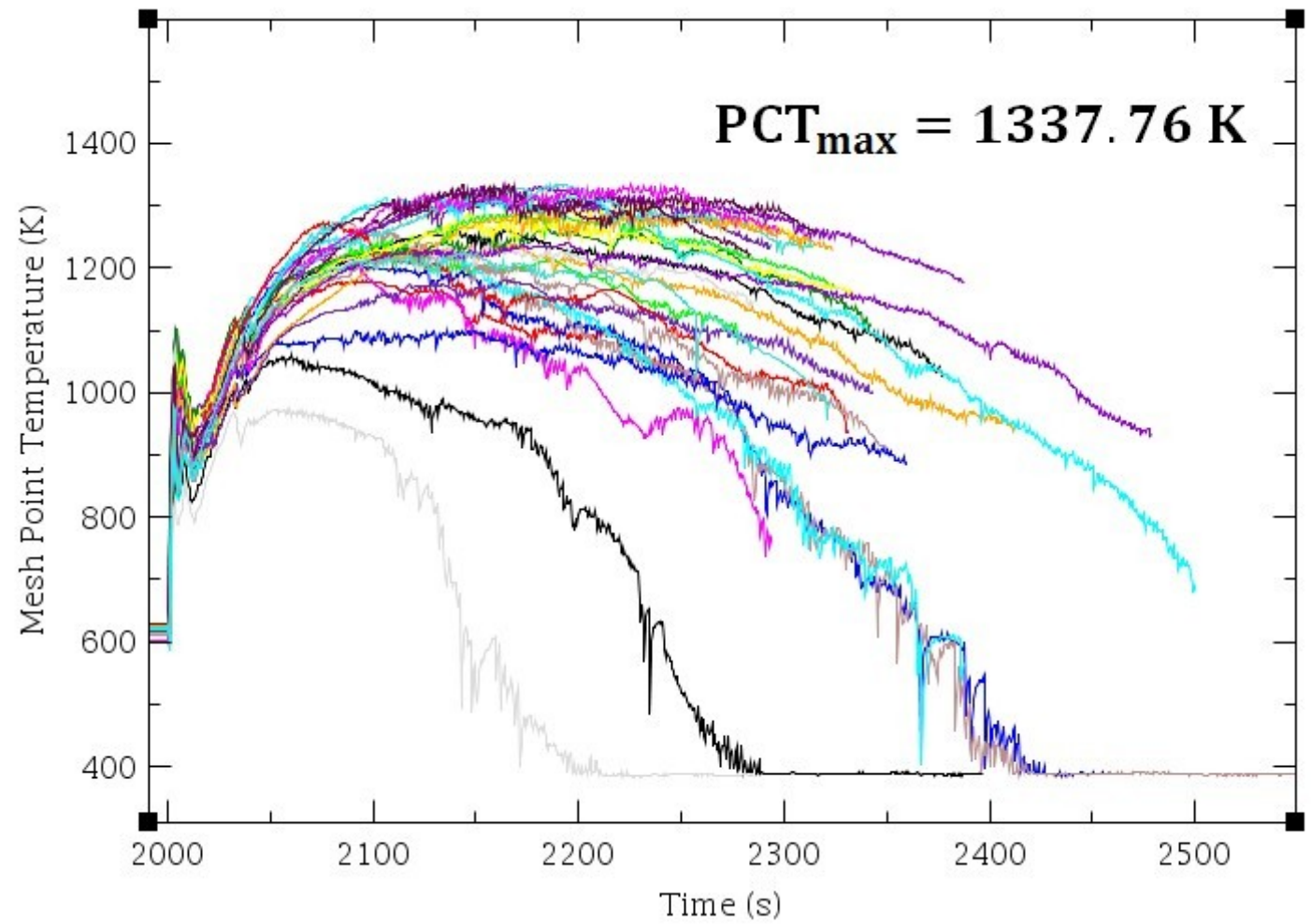

Figure 9. Calculated PCT of 59 Trials 